Kalpa Publications in Engineering
Volume 1, 2017, Pages 340-347
$\begin{aligned} & \text { ICRISET2017. International Conference on Re- } \\ & \text { search and Innovations in Science, Engineering } \\ & \text { \&Technology. Selected Papers in Engineering }\end{aligned}$

\title{
Productivity Improvement Using Motion Study \& Work Measurement in Permanent Magnet DC (PMDC) Motor
}

\author{
Mod.Jishankhan $^{* 1}$, Utkarsh Dubey ${ }^{* 2}$, Deep Patel ${ }^{* 3}$, Akil Jariya ${ }^{* 4}$ \\ *Department of Production Engineering, BVM Engineering College, V.V. Nagar-388120, India \\ 1: jishanpathan981@gmail.com, 2: udubey 1995 @yahoo.com, \\ 3: deeppatel018@gmail.com,4: akil.jariya@bvmengineering.ac.in
}

\begin{abstract}
In manufacturing sector, production time is an important factor in order to compete in market. This leads every management to decrease production time and increase quality of the product. In manufacturing industry in the production of product the main two kind of time consumption are Machining time and travel time also known as value added and non-value added time. Sometimes unnecessary or improper work cycle leads to delay in manufacturing. Hence, it is most important to identify that delay and minimize for positive benefit of company. As most of the industries bear losses due to nonproductive time in the manufacturing cycle and this paper give one of many solutions to increase the productive time. The main objective of this paper is to explain how the plant layout can with help of Motion study and Work Measurement to reduce lead-time and the manufacturing cycle time.
\end{abstract}

\section{Introduction}

We researched at Private Motor manufacturing firm It offers a comprehensive range of Permanent Magnet D.C. motors, Wound field D.C motors, Gear Motors, Battery Operated D.C. Motors, Speed Reducers and Custom PMDC motors engineered for high performance

We learnt about various process that take place during the production of a PMDC motor. We observed those processes and identified some flaws, which are responsible for low productivity, and with help of work measurement and motion study.

A permanent-magnet D.C. (PMDC) motor is similar to an ordinary D.C. shunt motor except that its field is provided by permanent magnets instead of salient-pole wound-field structure. Most of these motors usually run on $6 \mathrm{~V}, 12 \mathrm{~V}$ or $24 \mathrm{~V}$ dc supply obtained either from batteries or rectified alternating current. In such motors, torque is produced by interaction between the axial current-carrying rotor 
Productivity Improvement Using Motion Study ... Mod. J.Pathan, A. Jariya, D. Patel and U. Dubey

conductors and the magnetic flux produced by the permanent magnets. From the motion-operation chart it is clear that travel time consumes nearly $10 \%$ of total time which is non-value added which is required to be minimized, so we will first of all do the motion study of existing layout and then time study of that layout. After completing this procedure, we will do analysis of data and after that, we had made new layout which has minimum travelling distance and string diagram as simple as possible to reduce complexity and confusion in floor layout.

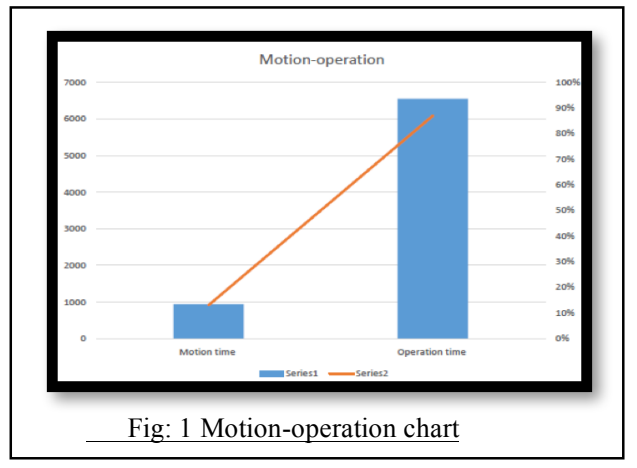

\section{Motion Study}

The following figures shows the existing layout of PMDC manufacturing unit. The layout is explained in detail in Motion study.

Following are the nomenclatures of figure:

1 shows the door area for entrance and exit, 2 shows empty space, 3 shows the bucket for raw material which contains stator frame, magnets, DEH, $\mathrm{CEH}$ circuit, 4 shows the oven which is used for Hot Gluing, 5 shows the Buffing Machine, 6 shows area used for storage of glued stator, 7 shows gluing table, 8 shows press machine, 9 shows work table, 10 shows shelf for raw material, 11 shows Fixture, 12 shows storage for hot glued product, 13 shows area storage for armature, 14 shows Fastener shelf, 15 shows tool storage shelf, 16 shows automatic buffing machine, 17 shows magnetizing machine, 18 shows press tool, 19 shows assembly table, 20 shows neutral axis testing machine, 21 shows no load tester, 22 shows

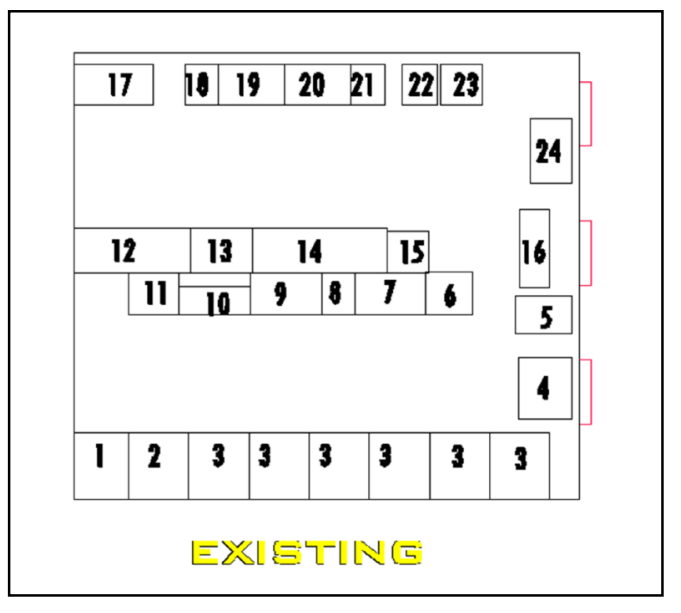
load testing machine, 23 shows trolley for transportation, 24 shows final assembly table.

\section{A. String diagram study of existing layout}

We have studied the motion using string Diagram method so that because it is the base of our layout improvement. String diagram of the existing layout is shown below 
Material is entered by door at 1 and is kept at empty space at 2 , and then moved to storage at 3. Some raw material is also stored at table 6. At starting, the material is taken to buffing at 5 and then taken to gluing at 7 . Then at oven for hot gluing at 4 . After process finishes at 4 it is moved to press machine at 8 . Table 10 is shelf for some raw material like glue, magnets etc. Table 13 stores armatures, table 14 for fasteners \& table 15 for tools. There is a horizontal $\mathrm{CNC}$ machine for machining process at table 16. After press, material is taken to worktable at 9 for the further process

to table 12 which will be cooled off for fixtures from table 11 for magnetizing. At table 17, the semifinished product is magnetized and is taken to table 18 for press fitting. After press fitting some assembly is done at table 19 with parts taken. Completed assembly goes to neutral axis checking on table 20. As soon as the neutral axis is okay, it is taken for load testing on table 21. Generator for load testing is kept at position 22. Finished product is finally stored in a trolley on 23 . And finishing \& branding is done on table 24 . We observed that productivity could be improved by bringing about small changes in the work floor layout.

The issues with the existing layout we find is "confusion regarding the magnetized and nonmagnetize product which is due to both magnetize and non-magnetize stator put at same place". Another issue that we find is "In buffing process as the worker had to bring the work pieces from different places" which resulted in increased production time and increased machine-running cost.

Movement 1 is material going from storage to buffing machine which consumes 19 sec. Movement 2 is buffing to hot gluing table travel which takes $15 \mathrm{sec}$. Movement 3 is from work table to oven and it takes 180 sec. Movement 4 which is the maximum time consuming travel which is oven to storage space and it takes whopping $670 \mathrm{sec}$. Movement 5

\begin{tabular}{|c|l|c|}
\hline Motion & \multicolumn{1}{|c|}{ Description } & Time(sec) \\
\hline 1 & Material storage to buffing machine & 19 \\
2 & Buffing machine to Hot gluing table & 15 \\
3 & Work Table to Oven & 180 \\
4 & Oven to storage space & 670 \\
5 & Storage space to magnetizing machine & 15 \\
6 & Magnetizing $\mathrm{m} / \mathrm{c}$ to storage & 6 \\
7 & Storage to assembly Table & 8 \\
8 & Assembly Table to neutral axis $\mathrm{m} / \mathrm{c}$ & 2 \\
9 & Neutral axis to Load tester $\mathrm{m} / \mathrm{c}$ & 20 \\
10 & Load testing $\mathrm{m} / \mathrm{c}$ to final assembly \\
\hline \multicolumn{2}{|c|}{ Fig: 4 Existing Layout Travel Time sheet } \\
\hline
\end{tabular}
is travel from storage space to magnetizing machine of $15 \mathrm{sec}$. Movement 6 is from magnetizing machine to storage is $6 \mathrm{sec}$. Movement 7 is from storage to assembly table of $8 \mathrm{sec}$. Movement 8 is smallest travel time of $2 \mathrm{sec}$ from assembly table to neutral axis machine. Movement 9 is from neutral axis to load testing machine of travel time $20 \mathrm{sec}$. Last movement 10 which is from load testing machine to final assembly which takes 21 secs.

As we did time study from next chapter it suggests that Motion time contributes $13 \%$ in Tact time. We also came to conclusion that operation time of process can't be reduce and it is as per the validation report. So, we focused our goal to the Motion study. So for the study of existing layout we made string diagram of existing layout. 
Productivity Improvement Using Motion Study ... Mod. J.Pathan, A. Jariya, D. Patel and U. Dubey

From the chart, we can see that Motion 3 and 4 are the bottleneck for the process and as they are really important can't be eliminated so we got the idea that we can reduce its effect if we will put the motion 3 and 4 path as short as possible and that's the foundation of our project. Therefore, we made new layouts for fulfilling our project definition

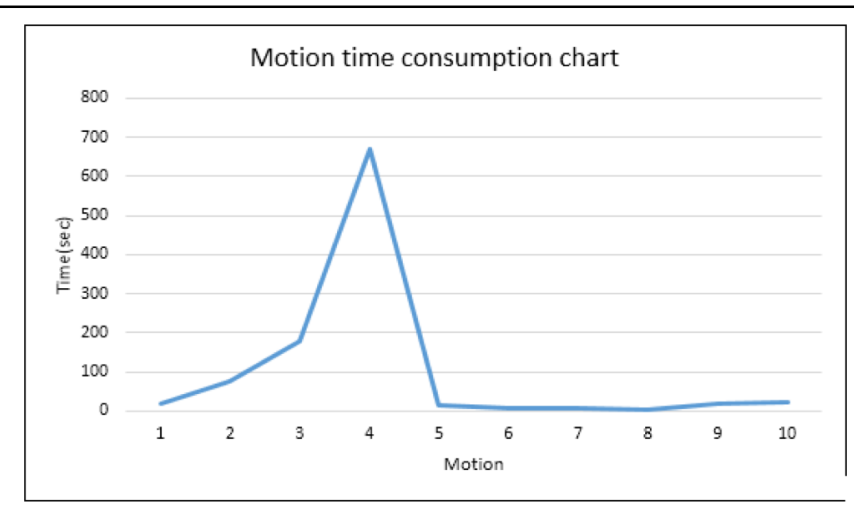

Fig: 5 Motion-time comparison chart

\section{Work}

\section{Measurement: Time Study}

We studied and recorded the various operations carried out by the operator and we made a time study sheet with allowance (5\% personal and 6\% Fatigue) according to Industrial Labor Organization.

\begin{tabular}{|c|c|c|c|c|c|c|c|c|c|c|c|c|}
\hline serial no. & Operation & & ervati & Time i & cond) & & $\mid \begin{array}{c}\text { Avg time } \\
\text { obsevered(second) }\end{array}$ & \begin{tabular}{|c|} 
Normal time $=$ Avg \\
observed time + \\
$5 \%$ personal \\
allowance $+6 \%$ \\
fatigue allowance
\end{tabular} & $\begin{array}{c}\text { lot } \\
\text { size(Nu } \\
\text { mber) }\end{array}$ & $\begin{array}{c}\text { Time } \\
\text { per lot }\end{array}$ & $\begin{array}{c}\text { Preparat } \\
\text { ion time }\end{array}$ & $\begin{array}{l}\text { Standar } \\
\text { d time }\end{array}$ \\
\hline 1 & Buffing & 28.4 & 33.1 & 37.7 & 39.6 & 38.8 & 35.52 & $40 \operatorname{secs}$ & 24 & 16 mins & $4 \operatorname{mins}$ & 20 mins \\
\hline 2 & Magnetization & 58 & 70 & 66 & 80 & 60 & 67 & 74.4 secs & 24 & 30 mins & $5 \mathrm{mins}$ & 36 mins \\
\hline 3 & Bearing fitting & 28.7 & 34.5 & 55.6 & 34.5 & 38 & 38.26 & $42.5 \mathrm{secs}$ & 24 & 17 mins & $1 \mathrm{mins}$ & 18 mins \\
\hline 4 & Assembly & 80 & 90 & 116 & 177 & 95 & 111.6 & 123.9 secs & 24 & 50 mins & $5 \mathrm{mins}$ & 55 mins \\
\hline 5 & Neutral Axis & 53.2 & 58.3 & 62.3 & 51.4 & 59.2 & 56.88 & $63.2 \mathrm{secs}$ & 24 & 26 mins & 2 mins & $28 \mathrm{mins}$ \\
\hline 6 & Final Assembly & 212 & 208 & 210 & 208 & 212 & 210 & $242 \operatorname{secs}$ & 1 & $232 \mathrm{sec}$ & $10 \mathrm{sec}$ & 242 secs \\
\hline 7 & Gluing : Frame+ Magnet & 63 & 67 & 62 & 68 & 65 & 65 & 75 secs & 1 & $72 \mathrm{sec}$ & $3 \mathrm{sec}$ & $75 \operatorname{secs}$ \\
\hline 8 & load testing & 106 & 108 & 109 & 104 & 103 & 106 & 120 secs & 1 & $118 \mathrm{sec}$ & $2 \mathrm{sec}$ & $120 \mathrm{secs}$ \\
\hline
\end{tabular}

As shown in figure 6: we have calculated the standard time for operation using stopwatch technique. As shown above table standard time for buffing a lot of 24 pieces is 20 minute. Standard time for magnetizing the stator is 36 minute per lot of 24 piece. Standard time for bearing fitting is 18 minute per lot of 24 piece. Standard time for assembly is 55 minute per lot of of 24 piece. Standard time for neutral axis checking is 28 minute per lot of 24 piece. Final assembly per piece takes 282 second(approx. 5 minute). Gluing takes 75 second per piece.

A. New Layout with string Diagram: 
Productivity Improvement Using Motion Study ... Mod. J.Pathan, A. Jariya, D. Patel and U. Dubey

We created the feasible optimum layout as shown below.

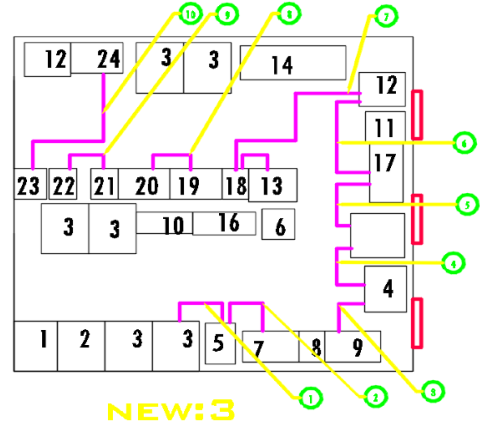

Fig: 7 New layout with string Diagram

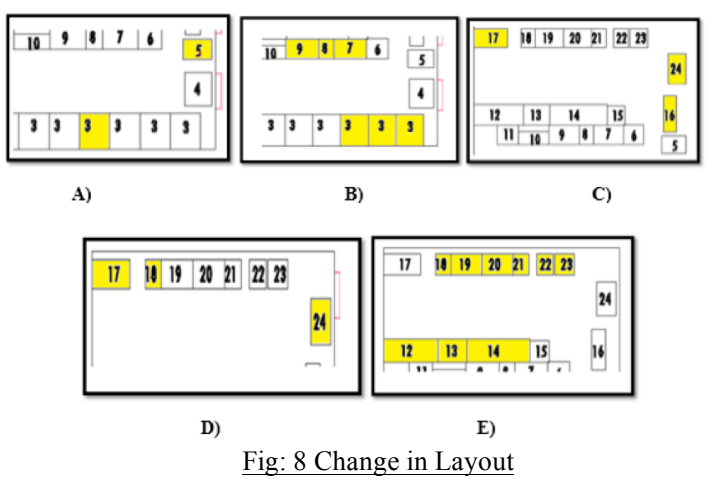

As shown in figure A) 5(Manual Buffing machine) is replaced to the place of 3(Raw material bucket). Because we want to make layout such that it's string diagram become as simple as possible and the string diagram lines do not cross each other.

As shown in figure B) 7(gluing table), 8(Gluing fixture), 9(Gluing Table) replaces three Buckets, so that 7(gluing table),8(Gluing fixture), 9 (Gluing Table) comes aside of manual buffing machine.

As shown in figure C) 17(Magnetizing Machine) replaces 24(Final assembly) and 16(Auto buffing) so that magnetizing machines comes aside of the oven.

As shown in figure E) 18(Bearing Press), 19(Assembly1), 20(No load test), 21-22(Load test), 23(trolley) replaces12-13(Material place), 14(fastener shelf).so that piece wise production can be achieved from that production line sequence.

As shown in figure D) 24(Final assembly table) replaces 17(Magnetizing Machine) 18(Bearing Press) so that final assembly comes at the exit part so the manufactured motor can be transferred easily.

\section{Benefit of new layout are as below:}

We have statistically proved that new time is $58 \%$ of original travel time and reduced $42 \%$ travel time. Which will reduce our overall Tact time for product.

Further due to new layout exit of the manufactured motor or route of exit is simplified. New layout reduces travel distance by $30 \%$ of total travel distance.

Further due to new layout armature stock comes near bearing press which also decrease travel time.

Therefore, after change of the layout we observed that our existing travel time 87 is reduced to 51 second as per Fig:9.

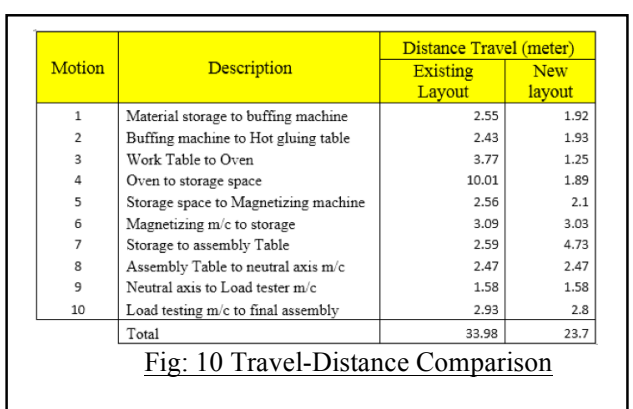

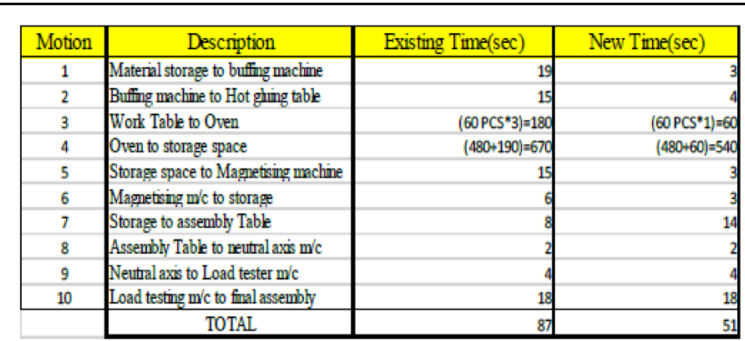

Fig:9. Comparison between Time consumption in Overall Manufacturing of a Motor 
Productivity Improvement Using Motion Study ... Mod. J.Pathan, A. Jariya, D. Patel and U. Dubey

Therefore, after change of the layout traveling distance is reduced from 33.98 to 23.7 meter as per So, Reduced time $=7485-7193=292 \mathrm{sec}=4.86$ minute

So, In one complete cycle of manufacturing we save time of around $292 \mathrm{sec}$. It can also be concluded that for one motor manufacturing we save time of 292 second.

We gathered the information information about the monthly production which is shown below,

Monthly Avg Demand = 6437

Monthly Avg Production $=6370$

Daily Avg production $=245$

Regular shift is 9 to $5: 30$

Lunch time is 12 to $12: 30$

Allowance take as $30 \mathrm{~min}$

Total working time : $7 \mathrm{hr} .30 \mathrm{~min}$

Total working time : $450 \mathrm{~min}$

So we can say that at every $110 \mathrm{sec}$ the firm is producing one motor.

So by using simple algebraic mathematics we can say that if in $7485 \mathrm{sec}$ cycle time production per day is 245 so at cycle time of 7193 production will be as follows,

Production $=(3.75 * 245) / 3.6=255$.

So monthly production $=6630$ 
Productivity Improvement Using Motion Study ... Mod. J.Pathan, A. Jariya, D. Patel and U. Dubey

\begin{tabular}{|c|c|c|c|}
\hline Task & Discription & $\begin{array}{l}\text { Current time } \\
\text { (sec) }\end{array}$ & $\begin{array}{l}\text { New time } \\
\text { (sec) }\end{array}$ \\
\hline 1 & $\begin{array}{l}\text { Row material frame unwraping and } \\
\text { taking to the buffing machine }\end{array}$ & 19 & 3 \\
\hline 2 & Buffing operation & 40 & 40 \\
\hline 3 & Cooling of buff part & 1800 & 1800 \\
\hline 4 & taking to the gluing table & 15 & 4 \\
\hline 5 & Gluing: Hot/Cold & 75 & 75 \\
\hline 6 & loading in oven & 180 & 60 \\
\hline 7 & Oven operation time & 3900 & 3900 \\
\hline 8 & Unloading in trolly & 480 & 480 \\
\hline 9 & $\begin{array}{l}\text { Trolly to near magnetizing machine } \\
\text { near place }\end{array}$ & 190 & 60 \\
\hline 10 & To magnetizing machine & 15 & 3 \\
\hline 11 & Magnetizing process & 75 & 75 \\
\hline 12 & Magnetizing to the bucket & 6 & 3 \\
\hline 13 & Bucket to bearing press & 8 & 14 \\
\hline 14 & Armature to bearing press & 5 & 2 \\
\hline 15 & Deh making & 60 & 60 \\
\hline 16 & Bearing press & 43 & 43 \\
\hline 17 & Assembly & 124 & 124 \\
\hline 18 & D.C. panel test on no load condition & 64 & 64 \\
\hline 19 & load testing & 120 & 120 \\
\hline 20 & load test to put at place & 8 & 8 \\
\hline 21 & Place to final asse table & 10 & 10 \\
\hline 22 & Final assembly & 242 & 242 \\
\hline 23 & Assemblt station to exit & 6 & 3 \\
\hline & Total time & 7485 & 7193 \\
\hline
\end{tabular}

Fig: 11 Overall-Time Comparison

\section{Conclusion}

By applying productivity improvement techniques motion study and work measurement, we have achieved our goal of productivity improvement. Our outcome is:

We have reduced $42 \%$ of travel time and traveling distance by $30 \%$. Thus, we have improved production and productivity by 4

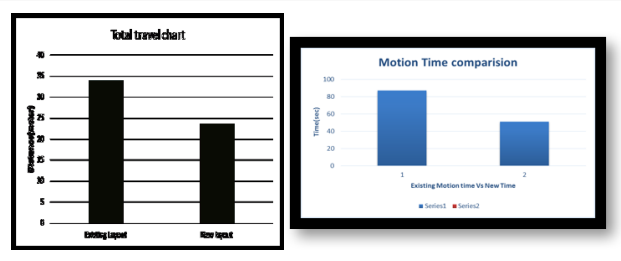


Productivity Improvement Using Motion Study ... Mod. J.Pathan, A. Jariya, D. Patel and U. Dubey

\section{References}

[1] Dr. A.K.Gupta, “Just in Time Revisited: Literature Review and Agenda for Future Research”,Dept. of Mech. Eng., DCR University of Science and Technology, Murthal, Sonepat, Haryana, India,ISSN : 2249-5762 (Online) | ISSN : 2249-5770 (Print)

[2] Ignatio Madanhire, Lovemore Kagande, Chancellor Chidziva, “Application of Just In Time (JIT) Manufacturing Concept in Aluminium Foundry Industry in Zimbabwe" International Journal of Science and Research (IJSR), India Online ISSN: 2319-7064

[3] Abdul Talib Bon, Daiyanni Daim, “Time Motion Study in Determination of Time Standard in Manpower Process”,3rd Engineering Conference on Advancement in Mechanical and Manufacturing for Sustainable Environment, April 14-16, 2010, Kuching, Sarawak, Malaysia

[4] David L. Danner., Marvin E. Mundel, Motion and Time Study (Paperback) Publisher: Prentice Hal.

[5] AIDT - Just-In-Time Manufacturing, ISO: 9001:2000, September 11, 2006.Page no :15-50

[6] Colin Drury, "Management Accounting for Business Decisions, 2nd Edition”,2001, pp: 473

[7] Vijaymohan P, Aravindha balaji S, "Lead Time Reduction in Windmill Control Panel Manufacturing", International Conference on Engineering Technology and Science- $\quad$ (ICETS'14) On 10th \& 11th February, Special Issue 1, February 2014

[8] Rajesh R. Pai, Sunith Hebbar, Vasanth Kamath and Giridhar Kamath,” Improvement of Process Productivity through Just-in-Time”, Research Journal of Management Sciences Vol. 2(12), 1-6, December (2013) 